Research Article

\title{
Laparoscopic retroperitoneal pyelolithotomy at UP Rural Institute of Medical Sciences and Research: our initial experience of 25 cases
}

\author{
Vikas Singh*, Poonam Gupta, Rudramani, Sunil K. Singh, Shesh Kumar, \\ Shashank Verma, Swadeep Srivastava
}

Department of Surgery, UP Rural Institute of Medical Sciences \& Research, Saifai, Etawah (UP)- 206301, India

Received: 29 March 2016

Accepted: 04 April 2016

*Correspondence:

Dr. Vikas Singh,

E-mail: drvikas_singh@yahoo.com

Copyright: (c) the author(s), publisher and licensee Medip Academy. This is an open-access article distributed under the terms of the Creative Commons Attribution Non-Commercial License, which permits unrestricted non-commercial use, distribution, and reproduction in any medium, provided the original work is properly cited.

\begin{abstract}
Background: To establish the feasibility of the retroperitoneal laparoscopic approach for treatment of patients with renal calculi who are under consideration for an open pyelolithotomy.

Methods: Laparoscopic retroperitoneal pyelolithotomy (LRP) was performed in twenty-five patients with renal calculi between 25 and $55 \mathrm{~mm}$ in largest diameter (solitary and staghorn). One of the patients also had multiple caliceal stones. These patients wanted an open procedure but had agreed to have their stone removal done laparoscopically in view of our experience. The classical retroperitoneal laparoscopic approach was used, and the trick to tackle some of the specific problems in such patients is also detailed.

Results: The stones were removed successfully in all the twenty-five patients, and there were no complications, except prolonged drainage of urine in one of them postoperative because of non-placement of double $J$ Stent intraoperatively.

Conclusions: Although no definitive conclusion can be drawn from this small series, the paper shows the feasibility of the retroperitoneal laparoscopic approach in a select group of patients with renal calculi. It also provides the technical tips for the beginners in the laparoscopic exploration of the retroperitoneal space more effectively.
\end{abstract}

Keywords: Laparoscopic retroperitoneal pyelolithotomy

\section{INTRODUCTION}

There is multimodality management for renal stones that has changed in the last two decades from invasive to minimally invasive to non-invasive procedures, with the advent of percutaneous nephrolithotomy (PCNL), extracorporeal shock wave lithotripsy (ESWL), and so on. The role of retroperitoneoscopic surgery is established for the removal of nonfunctioning kidneys and renal tumors1. However, the role of LRP in management of renal stones is yet to be established. Successful laparoscopic retroperitoneal management of renal stones has been described, ${ }^{2-11}$ although the indications have not been defined. This study is an endeavor to evaluate the role of LRP in the management of renal calculi and share our initial experience.

\section{METHODS}

The study was conducted at the Department of Surgery, UP Rural Institute of Medical Sciences \& Research, Saifai, Etawah (UP), India. Ethical committee of the institution approved it. The study included 15 cases of solitary renal calculus, 9 patients with staghorn calculi and 1 patient with multiple caliceal calculi. Informed written consent was taken from all the patients. The preoperative assessment of all the patients included the following investigations: plain X-ray of the KUB region, kidney function tests, namely, blood urea and serum creatinine, urine routine and microscopy, urine culture and antibiotic sensitivity, intravenous urography and ultrasound KUB. 
The mean stone size was less than or equal to $2.5 \mathrm{~cm}$. The parameters compared were feasibility, stone clearance, hospital stay, mean time to resume normal activities and the complications. The definition of stone clearance was the absence of any radio opaque shadow on plain X-ray KUB.

\section{Technique}

The first port was inserted through a $10 \mathrm{~mm}$ incision made just below the tip of the twelfth rib. The muscles were divided under vision; the dorsolumbar fascia was incised and the retroperitoneal space was entered. Indigenous gloved finger over a $5 \mathrm{~mm}$ port was inserted and inflated with saline (approximately 150-200 ml) for retroperitoneal space creation. The balloon was kept inflated for 3-5 minutes to achieve hemostasis. Other two ports were placed as per need, but maintaining the triangulation. The fourth port was placed as per the need for insertion of DJ stent intraoperatively. We preferred to approach the pelvis of the kidney directly, however in cases where the pelvis was either not easily accessible or there was an aberrant vessel, the upper end of the ureter was exposed and it was traced up to the pelvis. The pelvis was dissected and a pyelotomy incision was made with a hook dissector using monopolar cautery. The GilVernet's plane was dissected wherever necessary, to carry out extended pyelolithotomy. A longitudinal pyelotomy incision was made in patients of calculus in renal pelvis; however, in cases of extended pyelolithotomy, a curvilinear pyelotomy incision was made, with an extension of the incision into the appropriate calyx. After extraction of the calculus, the pyelotomy incision was closed meticulously with a 3-0 vicryl after placement of DJ stent intraoperatively. The operated area was drained with a tube drain and the wound closed. The drain was removed when the drainage was less than $25 \mathrm{ml} /$ day. The double ' $\mathrm{J}$ ' stent was removed on an outpatient basis. Post operatively; an Xray of the KUB was carried out after two weeks, to confirm stone clearance.

\section{RESULTS}

The average operating time was 90 minutes. Out of 25 patients who underwent LRP, 18 had extra renal pelvis while 7 patients had intrarenal pelvis. Blood loss varied from $15 \mathrm{~mL}$ to $60 \mathrm{~mL}$ with the average being $25 \mathrm{~mL}$. No blood transfusion was required in any of the patients. The drainage ranged from $700 \mathrm{~mL} /$ day to $50 \mathrm{~mL} /$ day. Average drainage was $100 \mathrm{~mL} /$ day in the first 48 hours. The drain removal ranged from 48 hours to 7 days. The drain was removed in the first 48 hours in 15 patients. The drain was removed whenever the drainage was less than $25 \mathrm{~mL} /$ day. Complete stone clearance occurred in 23 of the 25 patients $(92 \%)$ and 2 failures occurred, one in multiple caliceal calculi and the other in staghorn with caliceal component. The average duration of hospital stay was 5 days. Time taken to resume normal activities was 2 days. Two patients had peritoneal rents while performing retroperitoneal balloon dissection. Three patients had balloon rupture while the retroperitoneal space was being created. There were no vascular, visceral, or neural complications during the course of the study. Two conversions to open pyelolithotomy were necessary due to difficulty in localization, retrieval and bleeding; both were cases of caliceal calculi. Complications were there in the form of subcutaneous emphysema, which developed in 3 patients and prolonged drainage in 1 patient due to improper closure of extended pyelotomy incision.

Table 1: Comparative study of published series on laparoscopic pyelolithotomy.

\begin{tabular}{|llllll|l|}
\hline Series & No. of patients & $\begin{array}{l}\text { Age range } \\
\text { (Years) }\end{array}$ & M/F & Success & $\begin{array}{l}\text { Operating time } \\
\text { (Minutes) }\end{array}$ & $\begin{array}{l}\text { Blood loss } \\
(\mathbf{m L})\end{array}$ \\
\hline Gaur et al $^{7}$ & 8 & $22-65$ & $6: 2$ & $5(62 \%)$ & 120 & 132.9 \\
\hline Micali et al $^{8 *}$ & 11 & $22-75$ & - & $10(90 \%)$ & 249 & 127.2 \\
\hline Hemal et al $^{9}$ & 7 & $21-55$ & $5: 2$ & $5(71 \%)$ & 108.2 & 27 \\
\hline Chander et al $^{15}$ & 56 & $18-60$ & $1: 1.07$ & $54(96.4 \%)$ & 81 & \\
\hline
\end{tabular}

*Transperitoneal

\section{DISCUSSION}

The development of retroperitoneoscopic surgery including LRP has been slow compared with that of transperitoneal laparoscopic surgery due to the inability to establish adequate pneumoretroperitoneum with direct introduction of a needle into the retroperitoneum. However, the advent of the balloon dissection technique by Gaur in 1992 has opened new horizons in the field of retroperitoneoscopic surgery. ${ }^{6}$ Gaur et al reported a small series of 8 cases of retroperitoneoscopic pyelolithotomy in 1994 with a success rate of $62 \% .^{7}$ Subsequently, Micali et $\mathrm{al}^{8}$ reported a series of 11 cases and Hemal et $\mathrm{al}^{9}$ reported a series of 7 cases with success rates of $90 \%$ and $71 \%$, respectively. Of the 4 studies available for comparison, 3 adopted the retroperitoneal approach, and one was done through the transperitoneal route..$^{7-9,15}$

These studies had a small number of patients ranging from 7 to 11 with success rates varying from $62 \%$ to $90 \%$. However, in the study by Chander $\mathrm{J}$ et $\mathrm{al}^{15}$ in (2005), the success rate was $96.4 \%$. The success was $100 \%$ in pelvic calculi, and 2 failures occurred in caliceal calculi. As per our initial experience, the procedure is 
difficult for caliceal calculi unless the pelvicaliceal system is dilated and suitable instruments like flexible endoscopes will help in localization and extraction of caliceal calculi. Average operating time in other series ranged from 108 minutes to 249 minutes, while our study had mean operative time of 90 minutes which is comparable to the study by Chander $\mathrm{J}$ et al ( 81 minutes). Blood loss in our study was $25 \mathrm{~mL}$, which is comparable to that of other series, where it ranged from $15 \mathrm{~mL}$ to $132.9 \mathrm{~mL}$. The time taken to resume normal activities was 2 days.

In a study by Eterovic et al, ${ }^{10}$ it was shown that while open pyelolithotomy from day one continuously improves renal function, ESWL first decreases it and then over a period of months at best brings it back to the pretreatment level. These reports suggest that retroperitoneal laparoscopic pyelolithotomy, having procedural similarity to open pyelolithotomy, is not only nephron-sparing but also nephron-reviving.

Renal stones larger than $3 \mathrm{~cm}$ often require multiple ESWL or PCNL sessions, or both, with adjuvant endoscopic procedures and exposure to ionizing radiation in PCNL. Even after this, some patients may not be completely stone free. LRP can make these patients completely stone free in a single sitting with the added advantage of not being invasive to kidneys. However, this difference between LRP and other procedures is more pronounced when either the stone is large or multiple calculi are present. Retroperitoneoscopic pyelolithotomy can also be used in staghorn calculi, and the patient becomes stone free in a single sitting as compared with percutaneous nephrolithotomy, which requires multiple sittings, exposing the patient to ionizing radiation. ${ }^{11}$ Another advantage is that many auxiliary procedures like pyeloplasty and ureteric surgeries can be carried out in the same sitting. ${ }^{12}$

For patients with ectopic kidney, the results of ESWL are only moderately successful and PCNL is difficult; LRP is a viable alternative in such situations. Various authors ${ }^{13,14}$ have reported the laparoscopic approach for renal stones in patients with ectopically located kidney because the results of other minimally invasive techniques are only moderately successful.

A large number of patients with renal calculus disease in the developing countries are still being treated by an open operative procedure, as either the modern minimally invasive modalities are not available or they are beyond their access due to economical reasons. LRP can be considered an economically viable minimally invasive technique for these patients in developing countries like India.

LRP has a steep learning curve because of the relative absence of landmarks and the paucity of space, which makes this surgery difficult for beginners. The only constant landmark is the psoas muscle, but for surgeons experienced in open renal surgery, the learning curve is definitively shorter. Despite the learning curve, no significant complications occurred in this study.

In this series, the only significant complications were peritoneal rent, balloon rupture, subcutaneous emphysema, and prolonged drainage. Peritoneal rent happened mainly in thin individuals and due to initial balloon placement in wrong direction. The indigenous double-layered balloon did rupture in thin individuals and specially after inflating more than $200 \mathrm{ml}$ of saline.

Subcutaneous emphysema could be another major problem in LRP. Keeping the balloon inflated for 3 to 5 minutes to achieve perfect homeostasis can easily control the mild ooze from the retroperitoneal dissected area. The bleed from a specific operative site, can be minimized by precise knowledge of retroperitoneal anatomy and meticulous dissection. The use of a small gauge for control of minor bleed at the hilum is beneficial in most of the cases.

To decrease the morbidity related to prolonged drainage, meticulous closure of the renal pelvis should be carried out. Therefore, it is recommended that surgeons, who are well versed with intracorporeal knotting techniques, should perform this procedure.

The mean total analgesic requirement for LRP is $100 \pm 75$ $\mathrm{mg}$ of diclofenac, which is equivalent to 2 tablets of diclofenac.

\section{CONCLUSION}

LRP is a safe, simple, and effective minimally invasive procedure for management of renal calculi in patients with staghorn, large, and multiple calculi. Although at present, it seems relatively unsuitable for caliceal calculi, with more experience and the availability of flexible hand instruments, even caliceal calculi may become equally amenable to this procedure.

\section{Funding: No funding sources}

Conflict of interest: None declared

Ethical approval: The study was approved by the institutional ethics committee

\section{REFERENCES}

1. Doublet JD, Barreto HS, Degremont AC, Gattegno B, Thibault P. Retroperitoneal nephrectomy: comparison of laparoscopy with open surgery. World J Surg. 1996;20:713-6.

2. Rassweiler JJ, Henkel TO, Stock C, Greschner M, Becker P, Preminger GM et al. Retroperitoneal laparoscopic nephrectomy and other procedures in the upper retroperitoneum using a balloon dissection technique. Eur Urol. 1998;33(5):489-96. 
3. Uno Y, Katoh N, Kinukawa T, Matsura O, Ohshima S. Laparoscopic nephrectomy via the retroperitoneal approach. J Urol. 1996;156:1101-4.

4. Clayman RV, Kavoussi LR, McDougall EM, Soper NJ, Figenshau RS, Chandhoke PS et al. Laparoscopic nephrectomy: a review of 16 cases. Surg Laparosc Endosc. 1992;2(1):29-34.

5. Gill IS, Schweizer D, Hobart GM, Surg GT, Klein EA, Norvick AC. Retroperitoneal laparoscopic radical nephrectomy: the Cleveland experience. J Urol. 2000;163:1685-70.

6. Gaur DD. Laparoscopic operative retroperitoneoscopy: use of new device. J Urol. 1992;148:1137-9.

7. Gaur DD, Agarwal DK, Purohit KC, Darshne AS. Retroperitoneal laparoscopic pyelolithotomy. J Urol. 1994;151(4):927-9.

8. Micali S, Moore RG, Averch TD, Adams JB, Kavoussi LR. The role of laparoscopy in the management of renal and ureteric calculi. J Urol. 1997; 157:463-6.

9. Hemal AK, Goel A, Kumar M, Gupta NP. Evaluation of laparoscopic retroperitoneal surgery in urinary stone disease. $\mathbf{J}$ Endourol. 2001;15(7):701-5.

10. Eterovic D, Juretic-Kuscic L, Capkun V, Dujie Z. Pyelolithotomy improves while extracorporeal lithotripsy impairs kidney function. J Urol. 1999;161:39-44.

11. Gaur DD, Trivedi S, Prabhudesai MR, Gopichand M. Retroperitoneal laparoscopic pyelolithotomy for staghorn calculus. J Laparoendosc Adv Surg Tech A. 2002;12(4):299-303.

12. Ramakumar S, Lancini V, Chan DY, Parsons JK, Kavoussi LR, Jarrett TW. Laparoscopic pyeloplasty with concomitant pyelolithotomy. J Urol. 2002;167(3):1378-80.

13. Harmon WJ, Kleer E, Segura JW. Laparoscopic pyelolithotomy for calculus removal in a pelvic kidney. J Urol. 1996;155:2019-20.

14. Valdivia-Uria JG, Abrill Baquero G, Monzon Alegesque F, López López JA, Lanchares Santamaría E. Laparoscopic management of complex lithiasis in horse shoe kidneys [in Spanish]. Actas Urol Esp. 1994;18:346-50.

15. Chander J, Suryavanshi M, Lal P, Singh L, Ramteke VK. Retroperitoneal pyelolithotomy for management of renal calculi. SLS. 2005;9(1):97101.

Cite this article as: Singh V, Gupta P, Rudramani, Singh SK, Kumar S, Verma S, Srivastava S.

Laparoscopic retroperitoneal pyelolithotomy at UP Rural Institute of Medical Sciences and Research: our initial experience of 25 cases. Int Surg J 2016;3:48891. 